\title{
Course Objective Analysis of Physical Pollution Control Engineering
}

\author{
Haiying Zhang \\ School of Chemical and Environmental Engineering, Shanghai Institute of Technology, Shanghai, China
}

\begin{abstract}
Achievement degree of Physical Pollution Control Engineering is analyzed for students whose major is Environmental Engineering. Through learning of this course, the students can solve practical problems related to physical pollution control, and can also provide control procedure and measures. It is concluded that the average achievement degree is 0.71 for object $1,0.77$ for object 2 , and 0.47 for object 3 . Students have a relatively good grasp of object 1 and object 2 , while a low grasp of object 3 . Hence, object 3 should be strengthened in later class teaching.
\end{abstract}

\section{Introduction}

Physical Pollution Control Engineering is a required course for students whose major is Environmental Engineering [1]. It is supplied to meet requirement for scientific development and personnel training. Objective of this course is to teach basic knowledge of physical pollution control in class so that they can solve practical problems related to physical pollution control, providing control procedure and measures [2,3]. This course focuses on cultivating basic quality, basic technique and basic capacity of students. It is quite important to develop way of thinking and capacity of solving practical problems [4].

This course has three objectives. Firstly, this course is provided to get a general understanding on basic definitions of physical pollution, its damages and current status, types and basic control measures. Secondly, it is required to grasp noise measure, evaluation, impact prediction, noise reduction through absorption, sound insulation, noise elimination, and vibration isolation damping. In addition, students are also required to master control measures of physical pollution [5].

Table 1 Course objectives and requirements for students

\begin{tabular}{ccc}
\hline & Requirements for students & Course objective \\
\hline $\begin{array}{c}\text { Analysis of } \\
\text { questions }\end{array}$ & $\begin{array}{c}\text { It is required to recognize, analyze and perform scientific argumentation } \\
\text { on environmental problems using mathematics, natural science and } \\
\text { engineering science. }\end{array}$ & Objective 1 \\
$\begin{array}{c}\text { Design/development } \\
\text { of solutions }\end{array}$ & $\begin{array}{c}\text { It is required to give effective solutions for complex environmental } \\
\text { problems, and to design engineered technological process. }\end{array}$ & Objective 2 \\
$\begin{array}{c}\text { Engineering and } \\
\text { social }\end{array}$ & $\begin{array}{c}\text { It is required to master related background of environmental engineering, } \\
\text { and to get familiar to related laws and regulations. }\end{array}$ & Objective 3
\end{tabular}

\section{Relationship between course objective and requirement for graduates}

\subsection{Analysis of three objectives}

This course has the following requirements shown in Table 1. Through learning of this course, students are required to improve management and supervise capacity on physical pollution using basic knowledge and related laws and regulations. In addition, they are also required to improve capacity on environmental protection and environmental evaluation.

Three qualities should be cultivated. Firstly, it is required to set up environmental protection consciousness, through recognizing relationship between physical pollution and environment. Secondly, it is required to cultivate sense of social responsibility, through recognizing relationship between physical pollution and public health. Thirdly, it is required to set up value concept of health, safety and environmental protection, through recognizing of relationship between physical pollution and thereof. 


\subsection{Assessment method}

This course score depends on regular grade (including class performance and regular homework) and exam grade, which is shown in Table 2.

Table 2 Evaluation method of the final score

\begin{tabular}{|c|c|c|c|c|c|}
\hline \multirow[b]{3}{*}{$\begin{array}{c}\text { Course } \\
\text { objective }\end{array}$} & \multirow[b]{3}{*}{ Requirements for graduation } & \multicolumn{3}{|c|}{ Evaluation method and ratios } & \multirow[b]{3}{*}{ Ratios } \\
\hline & & \multicolumn{2}{|c|}{ Regular grade $(40 \%)$} & \multirow[b]{2}{*}{$\begin{array}{l}\text { Exam } \\
\text { grade } \\
(60 \%)\end{array}$} & \\
\hline & & $\begin{array}{c}\text { Class } \\
\text { performance }\end{array}$ & $\begin{array}{l}\text { Homework } \\
\text { and } \\
\text { attendance }\end{array}$ & & \\
\hline Objective 1 & $\begin{array}{l}\text { It is required to recognize, analyze and } \\
\text { perform scientific argumentation on } \\
\text { environmental problems using } \\
\text { mathematics, natural science and } \\
\text { engineering science. }\end{array}$ & $8 \%$ & 0 & $12 \%$ & $20 \%$ \\
\hline Objective 2 & $\begin{array}{c}\text { It is required to give effective solutions } \\
\text { for complex environmental problems, } \\
\text { and to design engineered technological } \\
\text { process. }\end{array}$ & 0 & $24 \%$ & $36 \%$ & $60 \%$ \\
\hline Objective 3 & $\begin{array}{l}\text { It is required to master related } \\
\text { background of environmental } \\
\text { engineering, and to get familiar to } \\
\text { related laws and regulations. }\end{array}$ & $8 \%$ & 0 & $12 \%$ & $20 \%$ \\
\hline
\end{tabular}

\section{Achievement analysis of course objective}

Evaluation composition is shown in Table 3. Regular grade is between $8 \%$ and $24 \%$ for different objectives, and exam grade is between $12 \%$ and $36 \%$ thereof. Choice question, computation, and simple answer are used to evaluate objective 1, object 2 and object 3 respectively.

\subsection{Evaluation items of course objectives}

Table 3 Evaluation composition of course objective

\begin{tabular}{|c|c|c|c|c|c|}
\hline Course objective & \multicolumn{3}{|c|}{ Evaluation composition } & Score & $\begin{array}{c}\text { Subtotal } \\
\text { score }\end{array}$ \\
\hline \multirow{2}{*}{ Objective 1} & Regular grade & & Class performance & 8 & \multirow{2}{*}{20} \\
\hline & Exam grade & 1 & Choice question & 12 & \\
\hline \multirow{3}{*}{ Objective 1} & Regular grade & & Homework and attendance & 24 & \multirow{2}{*}{60} \\
\hline & Exam grade & 2 & Computation & 36 & \\
\hline & Regular grade & & Class performance & 8 & \multirow[b]{2}{*}{20} \\
\hline Objective 1 & Exam grade & 3 & Simple answer question & 12 & \\
\hline Final score & & & & & 100 \\
\hline
\end{tabular}

\subsection{Achievement analysis for students who major this course}

Achievement analysis is shown in Table 4. Average score for object 1 is 14 , between 8 and 17 . The achievement degree is 0.71 . It indicates that students grasp most of subject 1, in terms of analysis and scientific argumentation on environmental problems using mathematics, natural science and engineering science. Similarly, the students also have a good grasp of subject 2, in terms of giving effective solutions for complex environmental problems, and designing engineered technological process. While, in terms of object 3, the achievement degree is very low. Hence, background of environmental engineering, and related laws and regulations should be strengthened in class teaching.

Table 4 achievement analysis of students learning this course

\begin{tabular}{cccccccc}
\hline & & \multicolumn{2}{c}{ Object 1 } & \multicolumn{2}{c}{ Object 2 } & \multicolumn{2}{c}{ Object 3 } \\
\cline { 3 - 7 } NO. & Student ID & $\begin{array}{c}\text { Score } \\
(20 \%)\end{array}$ & $\begin{array}{c}\text { Achievement } \\
\text { degree }\end{array}$ & $\begin{array}{c}\text { Score } \\
(60 \%)\end{array}$ & $\begin{array}{c}\text { Achievement } \\
\text { degree }\end{array}$ & $\begin{array}{c}\text { Score } \\
(20 \%)\end{array}$ & $\begin{array}{c}\text { Achievement } \\
\text { degree }\end{array}$ \\
1 & 1310701030 & 17 & 0.85 & 46 & 0.77 & 9 & 0.45 \\
2 & 1410700438 & 8 & 0.4 & 23 & 0.38 & 5 & 0.25 \\
3 & 1410700634 & 13 & 0.65 & 35 & 0.58 & 7 & 0.35 \\
4 & 1610700109 & 13 & 0.65 & 44 & 0.73 & 9 & 0.45
\end{tabular}




\begin{tabular}{cccc}
5 & 1610700110 & 15 & 0.75 \\
6 & 1610700111 & 11 & 0.55 \\
7 & 1610700113 & 10 & 0.5 \\
8 & 1610700115 & 15 & 0.75 \\
9 & 1610700129 & 14 & 0.7 \\
10 & 1610700308 & 16 & 0.8 \\
11 & 1610700309 & 16 & 0.8 \\
12 & 1610700319 & 17 & 0.85 \\
13 & 1610700321 & 15 & 0.75 \\
14 & 1610700402 & 16 & 0.8 \\
15 & 1610700421 & 14 & 0.7 \\
16 & 1610700440 & 14 & 0.7 \\
17 & 1610700524 & 12 & 0.6 \\
18 & 1610700537 & 17 & 0.85 \\
Average value & 14 & 0.71 \\
\hline \multicolumn{4}{c}{ As } \\
Assessment of achievement degree \\
on OBE and sustainable \\
elopment
\end{tabular}

\subsection{Analysis of objective 1}

Achievement degree analysis of object 1 is shown in Table 4 . The achievement degree is relatively close to the average value of 0.71 . It indicates that the students have a relatively good grasp of object 1 . Most of the students can recognize, analyze and perform scientific argumentation on environmental problems using mathematics, natural science and engineering science. A few students should be given much more guidance in learning object 1 .

\subsection{Analysis of objective 2}

Achievement degree analysis of object 2 is shown in Table 4 . The achievement degree is relatively dispersed to the average value of 0.77 . It indicates that the students make mistakes in computation, which should be strengthened in later teaching.

\subsection{Analysis of objective 3}

Achievement degree analysis of object 3 is shown in Table 4. The achievement degree is relatively low, with the average value of 0.47 . It indicates that it is relatively difficult for the students to grasp case analysis, which should be strengthened in later teaching. Practical cases should be provided in teaching, in terms of control physical pollution.

\section{Conclusions}

Most of the students can recognize, analyze and perform scientific argumentation on environmental problems using mathematics, natural science and engineering science. In addition they can give effective solutions for complex environmental problems, and to design engineered technological process. Practical case analysis is relatively difficult for students, which should be

\begin{tabular}{lccc}
58 & 0.97 & 12 & 0.6 \\
46 & 0.77 & 9 & 0.45 \\
42 & 0.70 & 8 & 0.4 \\
53 & 0.88 & 11 & 0.55 \\
53 & 0.88 & 11 & 0.55 \\
50 & 0.83 & 10 & 0.5 \\
54 & 0.90 & 11 & 0.55 \\
50 & 0.83 & 10 & 0.5 \\
55 & 0.92 & 11 & 0.55 \\
51 & 0.85 & 10 & 0.5 \\
55 & 0.92 & 11 & 0.55 \\
46 & 0.77 & 9 & 0.45 \\
28 & 0.47 & 6 & 0.3 \\
47 & 0.78 & 9 & 0.45 \\
46 & 0.77 & 9 & 0.47 \\
\hline
\end{tabular}

strengthened in later class teaching.

\section{References}

1. Mao Dongxing, Hong Zonghui. Environmental Noise Control Engineering. Beijing: Electronic Industry Press. 2015, P.105.

2. Li Lianshan. Physical Pollution Control Engineering. Beijing: Higher Education Press. 2014, P.202. [3] Chen, M. H: Master's Dissertation of National Cheng Kung University ( 2002 ).

3. Liu Huiling. Environmental Physical Pollution Control Engineering. Beijing: Electronic Industry Press. 2014, 102-115.

4. Kim, J. G: Dissertation of Washing- ton State University ( 2003 ).

5. Miles, M: Journal of Quality Management, Vol.4 (1999), p.111. 